\title{
Review
}

\section{Adult native knee extensor mechanism ruptures}

\author{
I.P. Pengas ${ }^{\mathrm{a}, *}$, A. Assiotis ${ }^{\mathrm{b}}$, W. Khan ${ }^{\mathrm{c}}$, T. Spalding ${ }^{\mathrm{a}}$ \\ ${ }^{a}$ UHCW (University Hospitals of Coventry \& Warwickshire NHS Trust), United Kingdom \\ b ST5 NW London Rotation, St Marys Hospital, United Kingdom \\ 'Division of Trauma \& Orthopaedics, University of Cambridge, Addenbrooke's Hospital, Cambridge, CB2 OQQ United Kingdom
}

\section{A R T I C L E I N F O}

\section{Keywords:}

Extensor mechanism

Quadriceps tendon rupture

Patella tendon rupture

Patella fracture

\begin{abstract}
A B S T R A C T
Extensor mechanism rupture is a serious event requiring prompt diagnosis and treatment. Patella fractures are reportedly six times more frequent than soft tissue injuries such as quadriceps or patella tendon ruptures. Classically quadriceps and patella tendon ruptures are seen more in males, with those over 40 predominantly suffering from quadriceps tendon ruptures, often associated with an underlying condition, whereas patella tendon ruptures are mostly associated with sport injuries and are commonly seen in the under 40s. Almost all types of extensor mechanism ruptures benefit from early management which typically involves surgery.

Diagnosis can be deemed easy to make by demonstrating inability to actively extend the knee, this however can be easily overlooked and missed in a busy emergency department leading to a late diagnosis and necessitating more complex surgery. Earlier surgical intervention and rehabilitation tend to produce improved outcomes.
\end{abstract}

Crown Copyright @ 2016 Published by Elsevier Ltd. All rights reserved.

\section{Contents}

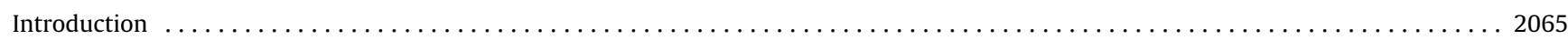

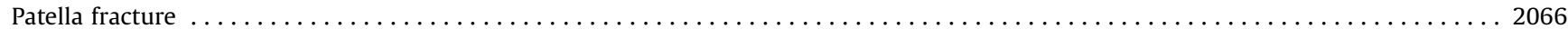

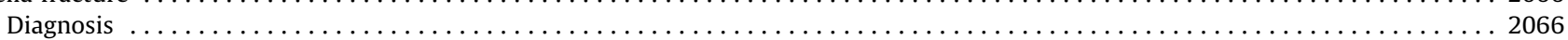

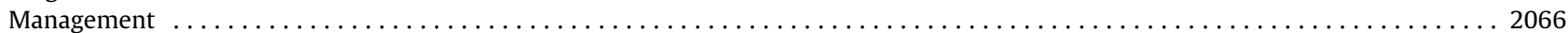

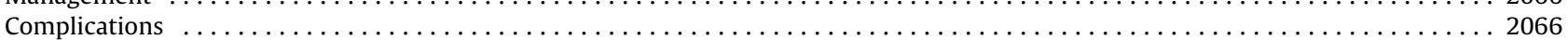

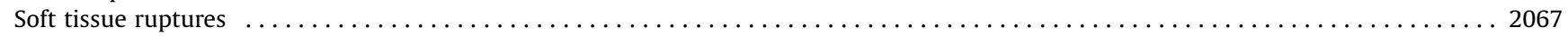

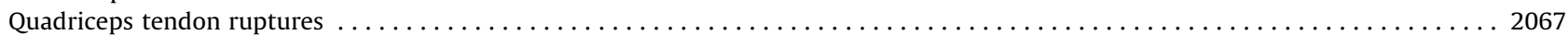

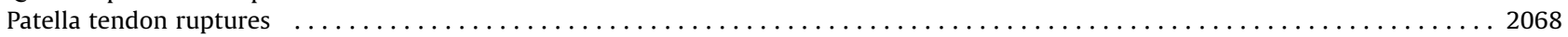

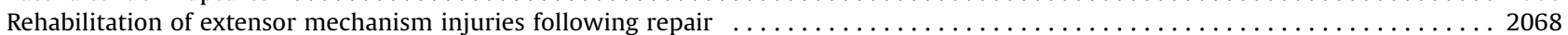

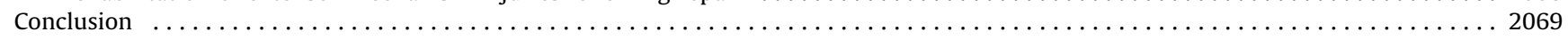

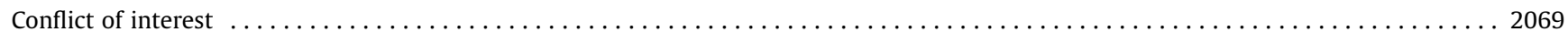

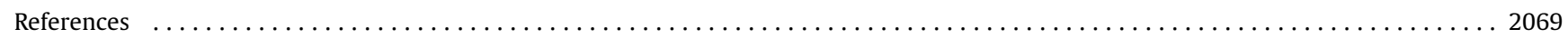

\section{Introduction}

The patella is the largest sesamoid bone and is the enveloped fulcrum of the extensor apparatus with the quadriceps and patella

\footnotetext{
* Corresponding author at: 40 Alma Rd, Romsey, Hampshire SO51 8ED, United Kingdom.

E-mail addresses: yiannispengas@yahoo.com, ioannis.pengas@nhs.net (I.P. Pengas), aassiotis9@homail.com (A. Assiotis),wasim.khan@ucl.ac.uk (W. Khan), tim@timspalding.com (T. Spalding).
}

tendons on either end. Quadriceps-generated forces converge through the patella tendon and patella retinaculae to the tibial tubercle. Discontinuation of the extensor mechanism from either patella fracture or tendon rupture, manifesting by an inability to achieve and maintain knee extension, is a highly disabling injury

Anatomically the quadriceps tendon consists of the tendinous coalescence of four muscles, all innervated by the femoral nerve. The rectus femoris, a double joint muscle, contributes only one fifth of the total generated force, with the remaining three single joint muscles (vastus lateralis, intermedius and medialis) being of greater importance to knee extension. The quadriceps muscle 
group attaches to the patella in three separate layers which consist of the rectus femoris superficially, vastus lateralis and medialis as the middle layer, with the deepest layer formed by vastus intermedius. The pre-patella fascia, formed by an expansion of the vasti and the fascia lata, is also involved in maintaining knee extension [1,2].

The patellar tendon (called a tendon not a ligament as the patella is a sesamoid bone) is the second strongest tendon after the Achilles tendon and is able to withstand forces up to 17.5 times body weight. It's made up from type I collagen (90\% of dry weight) and receives its blood supply from a number of sources, with the fat pad responsible for the posterior portion, the retinacular and recurrent tibial artery anteriorly, leaving the proximal and distal insertion areas relatively avascular and more susceptible to rupture $[3,4]$.

Disruption of the extensor mechanism can be divided into bony or soft tissue causes, due to either patella fracture or quadriceps and patella tendon ruptures caused by direct or indirect trauma.

\section{Patella fracture}

\section{Diagnosis}

Direct force onto the anterior part of the knee leads to patella compression resulting in significant cartilage damage followed by a fracture with a pattern that is often either stellate or multifragmentary. Indirect trauma, in the form of forceful eccentric or concentric quadriceps contraction, tends to lead to transverse superior or inferior pole avulsion patterns of fracture [5-7].

Classification systems ideally are designed to allow communication between physicians, guide treatment and predict outcomes. There is no universally accepted system to classify patella fractures, other than the AO/OTA classification system [8]. It comes as no surprise that commonly descriptive terminology such as transverse, stellate/comminuted, marginal, longitudinal, pole avulsion and osteochondral fracture seem to be preferred.

The diagnosis is often straight forward as the patient presents with a swollen, painful knee, incapable of active extension. On occasion signs can be more subtle and further investigations are required to identify the diagnosis.

Plain radiography is usually sufficient, with orthogonal anterior-posterior (AP) and lateral knee views supplemented with skyline views enabling identification of sagittal plane fractures (Fig. 1).

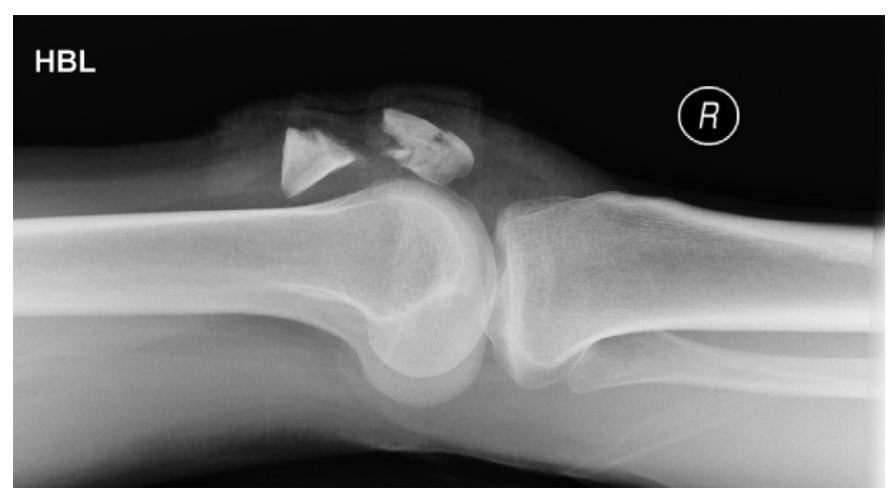

Fig. 1. Plain lateral radiograph of a patella fracture.

\section{Management}

Once the diagnosis and pattern of the patella fracture are established, treatment options fall between operative and nonoperative.

Excluding significant medical comorbidities as the sole indication, generally it seems that non-operative management can have satisfactory outcomes in fractures patterns with no or very little displacement $[5,9]$. This usually entails an above knee cast, from the malleoli to the greater trochanter, for 6 weeks. Earlier resumption of knee motion is advocated by some authors [9].

Operative intervention is indicated in all cases demonstrating an inability to straight leg raise and could be considered in patients who can straight leg raise but have an inter-fragmentary gap or articular step of $>2-3 \mathrm{~mm}$ noted on plain films. Although no clinical studies seem to have demonstrated that the $2-3 \mathrm{~mm}$ gap is the clinically significant cut-off, there seems to be a consensus in published literature, mainly in the form of literature reviews and expert opinions [10-12].

Open reduction and internal fixation is classically performed by the tension band wiring technique [13], although other authors have reported similar results with polyester sutures [14] or by passing the wires through cannulated screws and therefore reportedly avoiding k-wire related complications [15]. Good to excellent outcomes are observed in up to $80 \%$ of patients who underwent patella fixation with tension band wire [21,28]. Other authors have reported promising results with minimally invasive techniques [16,17] which perhaps on account of their technical difficulty have not become widespread in use.

Total patellectomy should be performed only in exceptional circumstances, such as when reconstruction is impossible, due to poor long term outcomes [18]. Specifically, although total patellectomy may address the problem of pain following a highly comminuted fracture, it significantly reduces the mechanical advantage to the extensor mechanism and results in a reduction to quadriceps strength by up to $49 \%$, making ascending stairs and negotiating deep seats difficult $[19,20]$. It may also result in ligament instability and atrophy of the quadriceps complex [20]. Partial patellectomy is preferable especially if large fragments with good articular surface are retained [5,21,22] demonstrating near normal outcomes. Even the retention of a small bony fragment has proven beneficial in maintaining the extensor mechanism lever arm [23]. Inferior pole patellectomy in highly comminuted or nonreconstructable fracture patterns, has been reported to lead to $78 \%$ good and very good results, demonstrating 85\% quadriceps strength as compared to the contralateral side at a mean 8.4 year follow-up [24].

In an attempt to preserve the distal pole, a basket plate enabling osteosynthesis was first introduced in 1988 in Croatia [25]. Although variations of the original plate have since been introduced, the basic design is that of a shaped plate to fit the geometry of the patella, which has a number of hooks and cancellous bone screw holes [25]. Results from the use of this implant were reported in 1996 [26] in a series of two patients and subsequently again in 2004 [27], demonstrating superior outcomes by preserving the inferior pole and preventing patella baja. The largest series was published in 2015 with 142 patients included and the authors reported mostly excellent and good functional outcomes as per the modified Cincinnati knee rating system [25].

\section{Complications}

Closed fractures have a reduced risk of deep infection and nonunion reported as $0-5 \%$ and less than $1 \%$ respectively, with open fracture rates much higher at $11 \%$ and $7 \%$, respectively $[6,28,29]$. 
Intolerance of hardware, such as k-wires, due to close proximity to the skin is the most frequent complaint, with implant removal reported from 0 to $60 \%$ and this inconsistency in published literature is put down to the variety of fixation techniques [30]. Symptomatic hardware rates appear to be similar in closed and open patellar fractures, as reported in a matched cohort study by Anand et al[31]. Kumar et al. demonstrated in a retrospective case series that prominent metalwork removal can vary with age, with $22 \%$ of their patients over the age of 60 needing this, whereas $40 \%$ of patients under the age of 60 needed metalwork removal[32]. This result was not reported as statistically significant by the authors attributed it to the differing demand levels of younger and older patients.

Knee stiffness is another complication recognized after patella fractures, with the length of immobilization not shown to be a significant factor [6,33]. Operative intervention and earlier mobilization has not shown to reduce the risk, with short lever arm manipulation under anaesthesia or arthroscopic arthrolysis recommended by Bell in an expert review article, if no improvement is observed after 6 months [30]. A similar suggestion was made by Kakazu and Archdeacon in their review, again based on expert opinion [11]. Sassoon et al. published the results of their retrospective case series, advocating manipulation under anaesthetic after at least 90 days following surgical fixation, although their cohort of 22 patients included only three patients with isolated patellar fractures [34].

Patellofemoral joint osteoarthritis has been observed following patella fractures, with Nummi reporting patello-femoral arthrosis in half of his study's patients at 2 years after injury [35]. Whether this is down to the quality of reduction or the traumatic primary injury, it still remains unclear [5,36,37].

Good results were reported following patello-femoral arthroplasty in a retrospective series by Argenson et al., using subjective outcome measures in patients with patellofemoral osteoarthritis of various causes, including 20 patients following patellar fracture [38]. Of interest was the fact that in the same study, post-fracture patients seemed to fare slightly worse after patellofemoral arthroplasty, when compared to patients with primary osteoarthritis or patients with osteoarthritis secondary to dysplasia. Other authors suggest distal patella realignment and off-loading procedures, such as Fulkerson or Maquet [39].

Where a patella fracture has been missed and is not tolerated due to pain or quadriceps insufficiency, this can be addressed in a stepwise manner and depending on the resulting late complication, such as non-union, delayed union and malunion. Although non-union or delayed union seem to be more common in transverse configuration fractures, they are infrequent events, with a combined incidence of up to $12.5 \%$, their treatment is often technically challenging [40].

A major determinant of the treatment choice should be the functional demands and pre-injury status of the patient. Klassen reported on a series of 20 patients who presented with a patellar fracture non-union and were treated either non-operatively or operatively. He reported that patients that are minimally symptomatic with patellar non-union or delayed union may be treated non-operatively, accepting that the fracture will not unite. On the other hand, he demonstrated that operative management usually leads to fracture union and improved knee function [41].

Specific surgical options largely depend on fracture pattern and chronicity and include simple freshening-up of the fracture site followed by tension band wiring [42], contralateral tendon-bonetendon-bone harvesting and reconstruction [43], partial patellectomy and total patellectomy as per the De La Caffiniere \& Theis technique [44]. Uvaraj et al. suggested the application of an initial cerclage wire for initial gross approximation of the fracture ends, followed by anterior tension band wiring and removal of the initial cerclage wire. In their series of 22 patients, they did not need to perform a quadricepsplasty in order to reduce the fragments [45].

Other options include a modified V-Y quadricepsplasty followed by fracture fixation or patellectomy, as described by Garg et al. in their retrospective series of 35 patients [46]. Their modification was introduced in order to manage the quadriceps contracture and is in the form of pre-operative traction of the proximal fragment with a skeletal pin-traction system for a few days, followed by the V-Y quadricepsplasty and fixation of the fracture.

Mal-united patella fractures with an articular step-off of $1 \mathrm{~mm}$ or higher presented with osteoarthritis more commonly than patients without an articular step, highlighting the importance of anatomical reduction when dealing with these fractures [47].

In a recent Cochrane review it was noted that percutaneous osteosynthesis may give better results than conventional open surgery, with biodegradable implants faring no better than metallic ones for displaced fractures and that patellectomy combined with vastus medialis advancement may be better than simple patellectomy. However the authors noted that available trials had small numbers of patients, emphasising the need for randomised controlled trials and that specific treatment options should be chosen on an individual patient basis [48].

\section{Soft tissue ruptures}

\section{Quadriceps tendon ruptures}

Quadriceps tendon ruptures are 8 times more common in males than females, mostly seen in those over 40 years old, peaking at the sixth and seventh decade. They have been noted to be twice as common in the non-dominant limb [49], with bilateral ruptures reported at around $12 \%$ of all ruptures [50] and black men exhibiting a 10 fold risk of quadriceps tendon rupture [51].

Quadriceps tendon rupture is usually associated with indirect trauma in a relatively hypovascular zone, $1-2 \mathrm{~cm}$ proximal to the superior pole of the patella, with patients under the age of 40 having mid-substance tears and those $>40$ years of age rupturing at the tendon-bone junction [52]. Such ruptures have also being associated with underlying systemic disease such as renal failure, rheumatoid arthritis, diabetes mellitus, hyperthyroidism, connective tissue disorders [53-56], as well as long term fluoroquinolone [57] and corticosteroid use which leads to fatty infiltration and weakening of the tendon [50].

The diagnosis is again based on failure of active knee extension, with an associated history of pain, occasionally an audible sensation of crepitus, along with signs of palpable gapping and/ or a suprapatellar mass due to tendon retraction. Plain radiographs may depict suprapatellar calcification, avulsion of a patella bony fragment, patellar spurs, dystrophic calcification within the tendon and patella baja $[1,58,59]$ (Fig. 2). Even with such typical signs and symptoms, up to $50 \%$ of cases have reportedly been missed in the emergency department [60]. If the diagnosis is in doubt or the extent of the tear is in question, an MRI scan may distinguish between complete or incomplete tears as well as give further information regarding the intra-articular state of the knee, as it provides a more visual depiction compared to ultrasound scanning [61].

Management is dependent on the extent as well as the location of tear. In partial ruptures, non-operative management with a cylinder cast for a minimum of 6 weeks, followed by a hinged brace allowing active extension in situ until pain resolves, has been suggested as adequate [62]. Acute complete tears benefit from transosseous repairs, as anchor suture fixation seems to be inadequate [63], and mid-substance tears require end-to-end repair and augmentation, which can be achieved by a reverse 


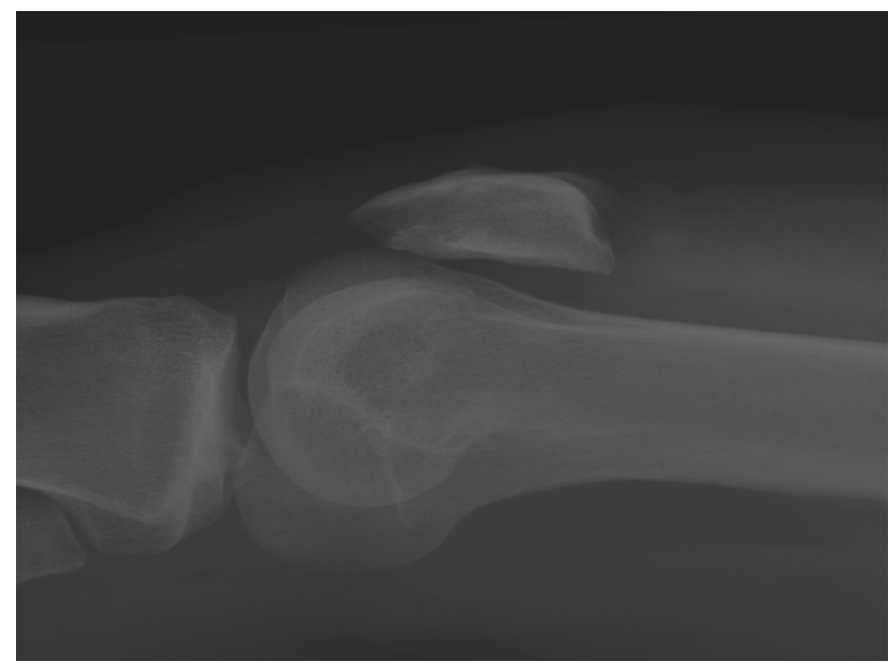

Fig. 2. Lateral knee radiograph demonstrating quadriceps tendon rupture with a proximal patella spur.

tendon Scuderi technique flap [64]. The results of early repairs are encouraging, with patients achieving satisfaction rates approaching $90 \%$ and return to function in the order of $80-90 \%[50,65,66]$.

Chronic quadriceps rupture on the other hand may be significantly more challenging due to tendon scarring and retraction, leading to poorer surgical outcomes when compared to acute repairs [65]. There are reports of favourable outcomes if the tendon can be approximated following medial and lateral releases [67]. When this proves impossible, surgical options include tendon lengthening techniques such as V-Y plasty and the Codvilla technique [54,64], hamstring grafting techniques [67] and synthetic Leeds -Keio ligament implantation, with the added benefit of its collagen inducing properties [68].

Recently, a novel technique using hamstring tendons along with a prolene mesh and autologous platelet rich plasma augmentation was described for a previously twice-failed repair as a salvage procedure [69].

\section{Patella tendon ruptures}

Patella tendon ruptures are infrequent events, usually seen in active under 40 s male patients following direct or indirect trauma. The latter is often in the form of a sudden quadriceps contracture with the knee flexed at around $60^{\circ}$. It is indeed more common to see the patella fracturing instead in such a scenario, suggesting that indirect patella tendon ruptures are perhaps the result of repetitive microtrauma [70-72]. Bilateral patella tendon ruptures are rare and have been reported in association with underlying pathologies [73]. Such pathologies according to a literature review by Rose and Frassica include systemic lupus erythematosus, renal failure, rheumatoid arthritis and primary hyperparathyroidism [74].

Rupture (Fig. 3 ) is usually followed by intense pain and inability to stand unaided and is associated with a haemarthrosis, a palpable gap and the inability to achieve or maintain knee extension against gravity, with patella alta [59] seen on plain films [71,75-77].

Associated injuries have been noted and include tibial plateau fractures, meniscal tears and intra-articular ligamentous ruptures. The use of MRI and ultrasound scanning has been advocated in order to identify these and assess the degree of tendon rupture, whether complete or incomplete [78,79].

Treatment is usually surgical, as neglected tears or nonoperative management leads to patella tendon retraction and

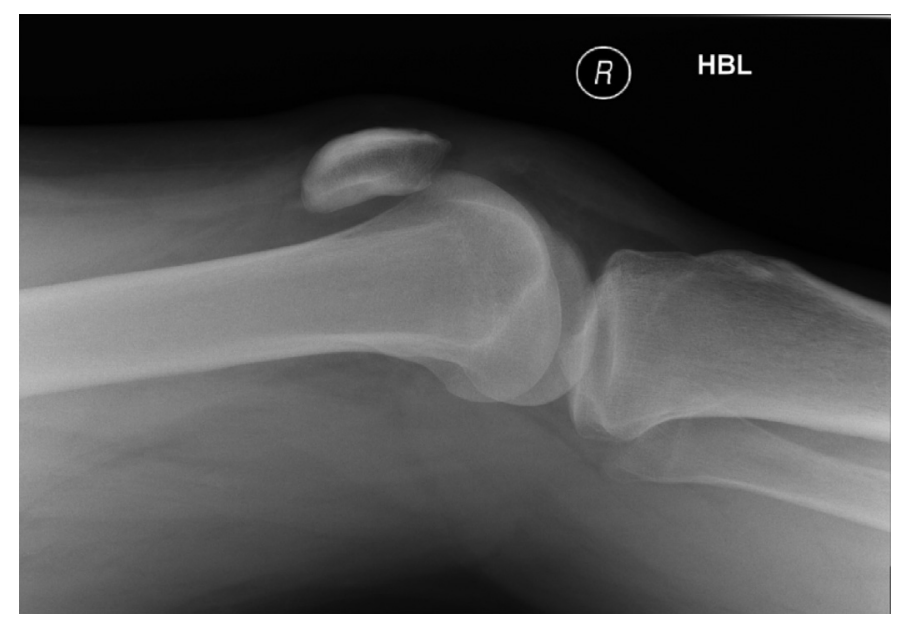

Fig. 3. Demonstrating patella tendon rupture with an associated patella alta.

scarring, loss of normal knee biomechanics and diminished long term function $[71,80]$.

The technique for repairing acute tears depends on the site of tear, with end-to-end absorbable suturing if mid-substance and through-transosseous tunnel suturing preferred for proximal or distal tears, with the use of heavy non-absorbable suture material $[73,80]$. The repair is often augmented with a frame-type configuration between the patella and tibial tuberosity, using either cerclage wire or a semitendinosus autograft. It is important to avoid patella baja by comparing the patella radiographically with the contralateral patella at $45^{\circ}$ degrees of flexion [71,76]. In proximal tendon avulsions, the tendon is anchored to the bone using custom-made bone anchors or non-absorbable sutures through two parallel patellar bone tunnels. Distal avulsions are rare in adults, and these can be managed with notched staples or bone anchors.

With regards to neglected or chronic tears, especially after the 6 week mark, retrieving the retracted patella is technically challenging with some authors suggesting a transpatellar traction of up to two weeks prior to reconstruction [75,81], usually requiring augmentation in the form of autografts, allografts or synthetics [71,76]. Examples of these include fascia lata or semitendinosus autografts, absorbable materials such as PDS or synthetics such as Dacron $[43,75,81,82]$. Another option suggested by Dejour et al. is the use of an autologous contralateral graft of tendon-bone-tendon-bone with the advantage of solid bone anchorage $[43,83]$. Allograft solutions such as Achilles tendon or patella tendon can also be used if needed [84].

Post operative outcomes often include some residual loss of quadriceps strength [85], which does not seem to be affected either by the type of tear or the type of repair [75]. Although early repair is defined as taking place within 3 weeks or less from injury [65], a negative correlation with outcome has been observed if the time interval of trauma to surgery exceeds one week [75]. However, favourable outcomes have been reported in 10 out of 13 chronic repairs, when using contralateral tendon-bone-tendon-bone autograft as described by Dejour et al. [83].

\section{Rehabilitation of extensor mechanism injuries following repair}

As the quadriceps complex is such a powerful muscle group, rehabilitation following patella tendon reconstruction should be cautious. Some authors recommend strict immobilisation for one 
month, followed by a further period of passive motion and eccentric exercises prior to allowing concentric exercises, aiming for full recovery by 4-6 months [1].

Biomechanical and anatomical studies have identified early mobilization as beneficial for tendon healing, maintenance of a healthier articular cartilage and maintaining joint motion, which in turn leads to reduced stiffness. This has prompted rehabilitation protocols that allow early passive flexion between $30^{\circ}-90^{\circ}$ of flexion from the first post-operative day [86,87]. Although these protocols have demonstrated a return to pre-injury sporting activity $[73,80,88]$, controversy remains over the optimal weightbearing status following surgery $[66,88,89]$.

The risk of re-rupture is of particular concern with up to $40 \%$ being reported in patients with previous total knee arthroplasty [90]. Studies have reported re-rupture rates of 1:21 following long leg cast immobilization [91], whereas those with early rehabilitation have a re-rupture rate of 1:39 [85], with Rougraff et al. finding no difference between early range of motion and immobilization [65]. To our knowledge, no randomized controlled trial has assessed rehabilitation protocols or specific surgical techniques [62], leaving the decision to the surgeon's experience and on a case by case basis.

\section{Conclusion}

Knee extensor mechanism rupture in adults mainly comprises patellar fractures, reported as six times more frequent than soft tissue tears of the quadriceps or patella tendons, with surgical intervention considered the gold-standard for the restoration of function when active extension is lost.

With regards to patellar fractures, tension band wiring and early range of motion rehabilitation tend to produce favourable outcomes, with every effort made to avoid patellectomy and preserve bone stock. Hardware removal, stiffness and patellofemoral joint secondary osteoarthritis have been described as potential complications of patella fractures and their treatment.

Quadriceps and patella tendon ruptures have improved outcomes when repaired early, with delayed repairs presenting technical challenges and often requiring augmentation techniques. Complications from these injuries include inability to return to pre-injury level of activity, loss of strength, risk of re-rupture and stiffness. Early rehabilitation protocols, especially when augmentation is utilized, tend to produce good results.

\section{Conflict of interest}

No Author of this review article has any disclosure to make. There is no conflict of interest regarding this article.

\section{References}

[1] Saragaglia D, Pison A, Rubens-Duval B. Acute and old ruptures of the extensor apparatus of the knee in adults (excluding knee replacement). Orthop Traumatol Surg Res 2013:99(Suppl. 1):S67-76.

[2] Andrikoula S, Tokis A, Vasiliadis HS, Georgoulis A. The extensor mechanism of the knee joint: an anatomical study. Knee Surg Sports Traumatol Arthrosc 2006;14(March (3)):214-20.

[3] Pang J, Shen S, Pan WR, Jones IR, Rozen WM, Taylor GI. The arterial supply of the patellar tendon: anatomical study with clinical implications for knee surgery. Clin Anat 2009;22(April (22)):371-6.

[4] Nemschak G, Pretterklieber ML. The patellar arterial supply via the infrapatellar fat pad (of Hoffa): a combined anatomical and angiographical analysis. Anat Res Int 2012;2012:713838.

[5] Bostrom A. Fracture of the patella: a study of 422 patellar fractures. Acta Orthop Scand 1972;143(Suppl):1-80.

[6] Carpenter JE, Kasman R, Matthews LS. Fractures of the patella. Instr Course Lect 1994:43:97-108.

[7] Bates DG, Hresko MT, Jaramillo D. Patellar sleeve fracture: demonstration with MR imaging. Radiology $1994 \mathrm{Dec} ; 193(3): 825-7$.
[8] Müller ME. The comprehensive classifiction of fractures of long bones. Berlin; New York: Springer-Verlag; 1990.

[9] Braun W, Wiedemann M, Ruter A, Kundel K, Kolbinger S. Indications and results of nonoperative treatment of patellar fractures. Clin Orthop Relat Res 1993;(April (289)):197-201.

[10] Schuett DJ, Hake ME, Mauffrey C, Hammerberg EM, Stahel PF, Hak DJ. Current treatment strategies for patella fractures. Orthopedics 2015;38(June (38)):377-84.

[11] Kakazu R, Archdeacon MT. Surgical management of patellar fractures. Orthop Clin North Am 2016;47(January (1)):77-83.

[12] Scolaro J, Bernstein J, Ahn J. Patellar fractures. Clin Orthop Relat Res 2011;469 (April (4)):1213-5.

[13] Muller M, Allgower M, Schneider R, Willenger H. Manual of internal fixation. 3rd ed. Berlin: Springer-Verlag; 1991.

[14] Gosal HS, Singh P, Field RE. Clinical experience of patellar fracture fixation using metal wire or non-absorbable polyester-a study of 37 cases. Injury 2001;32(March (2)):129-35.

[15] Berg EE. Open reduction internal fixation of displaced transverse patella fractures with figure-eight wiring through parallel cannulated compression screws. J Orthop Trauma 1997;11(November (8)):573-6.

[16] Luna-Pizarro D, Amato D, Arellano F, Hernandez A, Lopez-Rojas P. Comparison of a technique using a new percutaneous osteosynthesis device with conventional open surgery for displaced patella fractures in a randomized controlled trial. J Orthop Trauma 2006;20(September (8)):529-35.

[17] El-Sayed AM, Ragab RK. Arthroscopic-assisted reduction and stabilization of transverse fractures of the patella. Knee 2009;16(January (1)):54-7.

[18] Jakobsen J, Christensen KS, Rasmussen OS. Patellectomy-a 20-year follow-up. Acta Orthop Scand 1985;56(October (5)):430-2.

[19] Watkins MP, Harris BA, Wender S, Zarins B, Rowe CR. Effect of patellectomy on the function of the quadriceps and hamstrings. J Bone Joint Surg Am 1983;65 (March (3)):390-5.

[20] Sutton Jr. FS, Thompson CH, Lipke J, Kettelkamp DB. The effect of patellectomy on knee function. J Bone Joint Surg Am 1976;58(June (4)):537-40.

[21] Bostman O, Kiviluoto O, Santavirta S, Nirhamo J, Wilppula E. Fractures of the patella treated by operation. Arch Orthop Trauma Surg 1983;102(2):78-81.

[22] Goodfellow J, Hungerford DS, Zindel M. Patello-femoral joint mechanics and pathology. 1. Functional anatomy of the patello-femoral joint. J Bone Joint Surg Br 1976;58(August (3)):287-90.

[23] Duthie HL, Hutchinson JR. The results of partial and total excision of the patella. J Bone Joint Surg Br 1958;40-B(February (1)):75-81.

[24] Saltzman CL, Goulet JA, McClellan RT, Schneider LA, Matthews LS. Results of treatment of displaced patellar fractures by partial patellectomy. J Bone Joint Surg Am 1990;72(October (9)):1279-85.

[25] Matejcic A, Ivica M, Jurisic D, Cuti T, Bakota B, Vidovic D. Internal fixation of patellar apex fractures with the basket plate: 25 years of experience. Injury 2015;46(Suppl. 6):S87-90.

[26] Veselko M, Smrkolj V, Tonin M. Comminuted avulsion fractures of the inferior pole of the patella. Unfallchirurg 1996;99(January (1)):71-2.

[27] Kastelec M, Veselko M. Inferior patellar pole avulsion fractures: osteosynthesis compared with pole resection. J Bone Joint Surg Am 2004;86-A(April (4)):696701.

[28] Smith ST, Cramer KE, Karges DE, Watson JT, Moed BR. Early complications in the operative treatment of patella fractures. J Orthop Trauma 1997;11(April (3)):183-7.

[29] Catalano JB, Iannacone WM, Marczyk S, Dalsey RM, Deutsch LS, Born CT, et al. Open fractures of the patella: long-term functional outcome. J Trauma 1995;39 (September (3)):439-44.

[30] Bell J-C. In: Bently G, editor. Patella fractures. Springer; 2012.

[31] Anand S, Hahnel JC, Giannoudis PV. Open patellar fractures: high energy injuries with a poor outcome? Injury 2008;39(April (4)):480-4.

[32] Kumar G, Mereddy PK, Hakkalamani S, Donnachie NJ. Implant removal following surgical stabilization of patella fracture. Orthopedics 201033(May (5)).

[33] Bostman O, Kiviluoto O, Nirhamo J. Comminuted displaced fractures of the patella. Injury 1981;13(November (3)):196-202.

[34] Sassoon AA, Adigweme OO, Langford J, Koval KJ, Haidukewych GJ. Manipulation under anesthesia: a safe and effective treatment for posttraumatic arthrofibrosis of the knee. J Orthop Trauma 2015;29(December (12))e464-8 [Research Support, Non-U.S. Gov't].

[35] Nummi J. Fracture of the patella: a clinical study of 707 patellar fractures. Ann Chir Gynaecol Fenn Suppl 1971;179:1-85.

[36] Burvant JG, Thomas KA, Alexander R, Harris MB. Evaluation of methods of internal fixation of transverse patella fractures: a biomechanical study. J Orthop Trauma 1994:8(2):147-53.

[37] Edwards B, Johnell O, Redlund-Johnell I. Patellar fractures. A 30-year followup. Acta Orthop Scand 1989;60(December (6)):712-4.

[38] Argenson JN, Guillaume JM, Aubaniac JM. Is there a place for patellofemoral arthroplasty? Clin Orthop Relat Res. 1995;321(December):162-7.

[39] Ferguson Jr. AB, Brown TD, Fu FH, Rutkowski R. Relief of patellofemoral contact stress by anterior displacement of the tibial tubercle. J Bone Joint Surg Am 1979;61(March (2)):159-66.

[40] Nathan ST, Fisher BE, Roberts CS, Giannoudis PV. The management of nonunion and delayed union of patella fractures: a systematic review of the literature. Int Orthop [Review] 2011;35(June (6)):791-5.

[41] Klassen JF, Trousdale RT. Treatment of delayed and nonunion of the patella. J Orthop Trauma [Comparative Study] 1997;11(April (3)):188-94. 
[42] Satku K, Kumar VP. Surgical management of non-union of neglected fractures of the patella. Injury 1991;22(March (2)):108-10.

[43] Aït Si Selmi T, Neyret P, Rongieras F. Ruptures aiguës du ligament patellaire. Fractures du genou. Paris: Springer; 2005. p. 279-86.

[44] de la Caffiniere JY, Theis JC. Patellectomy with preservation of the leverage and continuity of the extensor system in patellar chondropathy. Rev Chir Orthop Reparatrice Appar Mot 1984;70(5):389-96.

[45] Uvaraj NR, Mayil Vahanan N, Sivaseelam A, Mohd Sameer M, Basha IM. Surgical management of neglected fractures of the patella. Injury 2007;38 (August (8)):979-83.

[46] Garg P, Sahoo S, Satyakam K, Biswas D, Garg A, Mitra S. Patellar nonunions: comparison of various surgical methods of treatment. Indian J Orthop 2012;46 (May (3)):304-11.

[47] Bostrom A. Longitudinal fractures of the patella. Reconstr Surg Traumatol $1974 ; 14(0): 136-46$.

[48] Sayum Filho J, Lenza M, Teixeira de Carvalho R, Pires OG, Cohen M, Belloti JC. Interventions for treating fractures of the patella in adults. Cochrane Database Syst Rev 2015;2:CD009651.

[49] Clayton RA, Court-Brown CM. The epidemiology of musculoskeletal tendinous and ligamentous injuries. Injury 2008;39(Decemeber (12)):1338-44.

[50] Vidil A, Ouaknine M, Anract P, Tomeno B. Trauma-induced tears of the quadriceps tendon: 47 cases. Rev Chir Orthop Reparatrice Appar Mot 2004;90 (February (1)):40-8.

[51] Owens B, Mountcastle S, White D. Racial differences in tendon rupture incidence. Int J Sports Med 2007 Jul;28(7):617-20.

[52] Yepes H, Tang M, Morris SF, Stanish WD. Relationship between hypovascular zones and patterns of ruptures of the quadriceps tendon. J Bone Joint Surg Am 2008;90(October (10)):2135-41.

[53] MacEachern AG, Plewes JL. Bilateral simultaneous spontaneous rupture of the quadriceps tendons: five case reports and a review of the literature. J Bone Joint Surg Br 1984;66(January (1)):81-3.

[54] Ilan DI, Tejwani N, Keschner M, Leibman M. Quadriceps tendon rupture. J Am Acad Orthop Surg 2003;11(May-June (3)):192-200.

[55] Shiota E, Tsuchiya K, Yamaoka K, Kawano O. Spontaneous major tendon ruptures in patients receiving long-term hemodialysis. Clin Orthop Relat Res 2002;(January (394)):236-42.

[56] Hardy JR, Chimutengwende-Gordon M, Bakar I. Rupture of the quadriceps tendon: an association with a patellar spur. J Bone Joint Surg Br 2005;87 (October (10)):1361-3.

[57] Khaliq Y, Zhanel GG. Musculoskeletal injury associated with fluoroquinolone antibiotics. Clin Plast Surg 2005;32(October (4))495-502 vi.

[58] Assiotis A, Pengas I, Vemulapalli K. Bilateral quadriceps tendon rupture in a seasoned marathon runner with patellar spurs. Grand Rounds 2011;11:77-80.

[59] Grelsamer RP, Meadows S. The modified Insall-Salvati ratio for assessment of patellar height. Clin Orthop Relat Res 1992;(September (282)):170-6.

[60] Neubauer T, Wagner M, Potschka T, Riedl M. Bilateral, simultaneous rupture of the quadriceps tendon: a diagnostic pitfall? Report of three cases and metaanalysis of the literature. Knee Surg Sports Traumatol Arthrosc 2007;15 (January (1)):43-53.

[61] Zeiss J, Saddemi SR, Ebraheim NA. MR imaging of the quadriceps tendon: normal layered configuration and its importance in cases of tendon rupture. AJR Am J Roentgenol 1992;159(November (5)):1031-4.

[62] Hak DJ, Sanchez A, Trobisch P. Quadriceps tendon injuries. Orthopedics 2010;33(January (1)):40-6.

[63] Lighthart WA, Cohen DA, Levine RG, Parks BG, Boucher HR. Suture anchor versus suture through tunnel fixation for quadriceps tendon rupture: a biomechanical study. Orthopedics 2008;31(May (5)):441.

[64] Scuderi C. Ruptures of the quadriceps tendon; study of twenty tendon ruptures. Am J Surg 1958;95(April (4)):626-34.

[65] Rougraff BT, Reeck CC, Essenmacher J. Complete quadriceps tendon ruptures. Orthopedics 1996;19(June (6)):509-14.

[66] Rasul Jr. AT, Fischer DA. Primary repair of quadriceps tendon ruptures. Results of treatment. Clin Orthop Relat Res 1993;(April (289)):205-7.
[67] Leopardi P, Vico G, Rosa D, Cigala F, Maffulli N. Reconstruction of a chronic quadriceps tendon tear in a body builder. Knee Surg Sports Traumatol Arthrosc. 2006;14(October (10)):1007-11.

[68] Rust PA, Tanna N, Spicer DD. Repair of ruptured quadriceps tendon with LeedsKeio ligament following revision knee surgery. Knee Surg Sports Traumatol Arthrosc 2008;16(April (4)):370-2.

[69] Rehman H, Kovacs P. Quadriceps tendon repair using hamstring, prolene mesh and autologous conditioned plasma augmentation. A novel technique for repair of chronic quadriceps tendon rupture. Knee 2015;(May):20.

[70] Zernicke RF, Garhammer J, Jobe FW. Human patellar-tendon rupture. J Bone Joint Surg Am 1977;59(March (2)):179-83.

[71] Kellersmann R, Blattert TR, Weckbach A. Bilateral patellar tendon rupture without predisposing systemic disease or steroid use: a case report and review of the literature. Arch Orthop Trauma Surg 2005;125(March (2)):127-33.

[72] Kelly DW, Carter VS, Jobe FW, Kerlan RK. Patellar and quadriceps tendon ruptures-jumper's knee. Am J Sports Med 1984;12(September-October (5)):375-80.

[73] Maffulli N, Wong J. Rupture of the Achilles and patellar tendons. Clin Sports Med 2003;22(October (4)):761-76.

[74] Rose PS, Frassica FJ. Atraumatic bilateral patellar tendon rupture, A case report and review of the literature. J Bone Joint Surg 2001;83-A(Sepetember (9)) 1382-6 volume. [Case Reports. Review].

[75] Siwek CW, Rao JP. Ruptures of the extensor mechanism of the knee joint. J Bone Joint Surg Am 1981;63(July (6)):932-7.

[76] Kasten P, Schewe B, Maurer F, Gosling T, Krettek C, Weise K. Rupture of the patellar tendon: a review of 68 cases and a retrospective study of 29 ruptures comparing two methods of augmentation. Arch Orthop Trauma Surg 2001;121 (November (10)):578-82.

[77] Enad JG. Patellar tendon ruptures. South Med J 1999;92(June (6)):563-6.

[78] Yu JS, Petersilge C, Sartoris DJ, Pathria MN, Resnick D. MR imaging of injuries of the extensor mechanism of the knee. Radiographics 1994;14(May (3)):541-51.

[79] Peace KA, Lee JC, Healy J. Imaging the infrapatellar tendon in the elite athlete. Clin Radiol 2006;61(July (7)):570-8.

[80] Bhargava SP, Hynes MC, Dowell JK. Traumatic patella tendon rupture: early mobilisation following surgical repair. Injury 2004;35(January (1)):76-9.

[81] Ecker ML, Lotke PA, Glazer RM. Late reconstruction of the patellar tendon. J Bone Joint Surg Am 1979;61(Sepetember (6A)):884-6.

[82] Levy M, Goldstein J, Rosner M. A method of repair for quadriceps tendon or patellar ligament (tendon) ruptures without cast immobilization. Preliminary report. Clin Orthop Relat Res 1987;(May (218)):297-301.

[83] Dejour H, Denjean S, Neyret P. Treatment of old or recurrent ruptures of the patellar ligament by contralateral autograft. Rev Chir Orthop Reparatrice Appar Mot 1992;78(1):58-62.

[84] Burks RT, Edelson RH. Allograft reconstruction of the patellar ligament. A case report. J Bone Joint Surg Am 1994;76(July (7)):1077-9.

[85] Konrath GA, Chen D, Lock T, Goitz HT, Watson JT, Moed BR, et al. Outcomes following repair of quadriceps tendon ruptures. J Orthop Trauma 1998;12(May (4)):273-9.

[86] Wang JH. Mechanobiology of tendon. J Biomech 2006;39(9):1563-82.

[87] Benjamin M, Kaiser E, Milz S. Structure-function relationships in tendons: a review. J Anat 2008;212(March (3)):211-28.

[88] West JL, Keene JS, Kaplan LD. Early motion after quadriceps and patellar tendon repairs: outcomes with single-suture augmentation. Am J Sports Med 2008;36 (Fewbruary (2)):316-23.

[89] Richards DP, Barber FA. Repair of quadriceps tendon ruptures using suture anchors. Arthroscopy 2002;18(May-June (5)):556-9.

[90] Dobbs RE, Hanssen AD, Lewallen DG, Pagnano MW. Quadriceps tendon rupture after total knee arthroplasty. Prevalence, complications, and outcomes. J Bone Joint Surg Am 2005;87(January (1)):37-45.

[91] Ramseier LE, Werner CM, Heinzelmann M. Quadriceps and patellar tendon rupture. Injury 2006;37(June (6)):516-9. 